\title{
Highly derived eutherian mammals from the earliest Cretaceous of southern Britain
}

Steven C. Sweetman, Grant Smith, and David M. Martill

Acta Palaeontologica Polonica 62 (4), 2017: 657-665 doi:https://doi.org/10.4202/app.00408.2017

Eutherian mammals (Placentalia and all mammals phylogenetically closer to placentals than to marsupials) comprise the vast majority of extant Mammalia. Among these there is a phenomenal range of forms and sizes, but the origins of crown group placentals are obscure. They lie within the generally tiny mammals of the Mesozoic, represented for the most part by isolated teeth and jaws, and there is strongly conflicting evidence from phenomic and molecular data as to the date of origin of both Eutheria and Placentalia. The oldest purported eutherians are Juramaia from the Upper Jurassic of China, and Eomaia and Acristatherium from the Lower Cretaceous, also of China. Based on dental characters and analyses of other morphological and molecular data, doubt has recently been cast on the eutherian affinities of the Chinese taxa and consequently on the date of emergence of Eutheria. Until now, the only tribosphenic mammal recorded from the earliest Cretaceous (Berriasian) Purbeck Group of Britain was the stem tribosphenidan Tribactonodon. Here we document two new tribosphenic mammals from the Purbeck Group, Durlstotherium gen. nov. and Durlstodon gen. nov., showing highly derived eutherian molar characters that support the early emergence of this clade, prior to the Cretaceous.

Key words: Mammalia, Eutheria, dentition, Early Cretaceous, Purbeck Group, Britain, UK.

Steven C. Sweetman [steven.sweetman@port.ac.uk], Grant Smith [grant.smith1@ myport.ac.uk ], and David M. Martill [david.martill@ port.ac.uk], University of Portsmouth, School of Earth and Environmental Sciences, Burnaby Building, Burnaby Road, Portsmouth, PO1 3QL, UK.

This is an open-access article distributed under the terms of the Creative Commons Attribution License (for details please see creativecommons.org), which permits unrestricted use, distribution, and reproduction in any medium, provided the original author and source are credited. 
For 5 Full text (365.1 kB) 